\title{
Comparison of 16S rRNA Sequences from the Family Pasteurellaceae: Phylogenetic Relatedness by Cluster Analysis
}

\author{
By PAUL J. CHUBA, RENATE BOCK, GABRIELE GRAF, \\ THOMAS ADAM AND ULF GÖBEL* \\ Institut für Medizinische Mikrobiologie und Hygiene der Universität Freiburg, Herman Herder \\ Strasse 11, D-7800 Freiburg, FRG
}

(Received 25 January 1988; revised 28 March 1988)

\begin{abstract}
The taxonomy of the family Pasteurellaceae has remained controversial despite investigations of biochemistry, serology, and nucleic acid relatedness. In an attempt to resolve some of this confusion, we have partially sequenced the $16 \mathrm{~S}$ rRNAs of seven members of the family, representing all three genera. The sequences were aligned, similarity scores calculated, and single, average and complete linkage cluster analysis of the resulting distance matrix performed. In this way, an evolutionary branching pattern of these closely related species was recontructed, and the approximate phylogenetic position of the family determined. Actinobacillus (Haemophilus) actinomycetemcomitans clustered with Haemophilus instead of Actinobacillus, supporting transfer of this species to the genus Haemophilus. Thus cluster analysis of phylogenetic relatedness was found to be particularly useful for studying closely related organisms, and could be performed using a microcomputer.
\end{abstract}

\section{INTRODUCTION}

Pasteurellaceae is one of three families of Gram-negative facultative anaerobes, many of which are pathogenic for humans and animals. Phylogenetically these organisms belong to the gamma subgroup of the purple bacteria, clustering closely with the Enterobacteriaceae and the Vibrionaceae in 16S rRNA cataloguing studies (Woese et al., 1985). They exhibit considerable interrelatedness as evidenced by biochemistry (Broom \& Sneath, 1981; Brondz \& Olsen, 1985; Sneath \& Stevens, 1985), serology (Potts et al., 1985; MacInnes \& Rosendal, 1987), nucleic acid hybridization (Christiansen et al., 1981; Potts \& Berry, 1983; Coykendall et al., 1983), and genetic transformation (Albritton et al., 1986). Such data have indicated that the generic descriptions within this family (Pasteurella, Haemophilus and Actinobacillus) may need redefinition (Pohl et al., 1983; Mutters et al., 1984; Bisgaard et al., 1986). In particular, it has been suggested that Actinobacillus actinomycetemcomitans be transferred to the genus Haemophilus (Potts et al., 1985). As outlined below, it appears that direct sequencing of 16S rRNAs would be useful in better defining genetic relatedness within the Pasteurellaceae.

Mutations occur in macromolecules as a quasi clock-like process and the use of comparisons of primary sequences of homologous macromolecules to infer evolutionary relationships has attracted considerable attention (Zuckerkandl \& Pauling, 1965; Wilson et al., 1987). The 16S rRNA molecule is particularly well suited to such studies (for reviews see Olsen et al., 1986: Woese, 1987), as relatively conserved regions of the 16S rRNA sequence can be used to study the relatedness of distantly related species, whereas variable regions can be used for the analysis of closely related species. To date, considerable progress has been made in establishing the major phylogenetic branches, based both on direct sequencing (Pace et al., 1986) and on oligonucleotide cataloguing methods (Fox et al., 1980). Recently, a method for the rapid

Abbreviations: $I / L$, identities per unit length; NAS, normalized alignment score.

0001-4650 C 1988 SGM 
(a)

GGGGGAACCCNGACGCAGCCCUGCCGCGUGAAUGAAGAAGGCUUCGGGUU 1 $\ldots$. . . . . . . . . . . . . . . . .

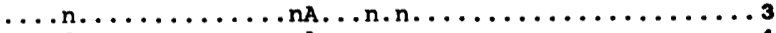

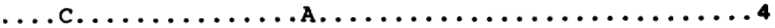

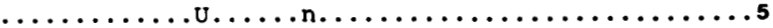

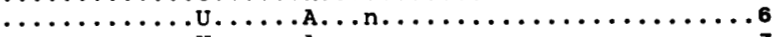

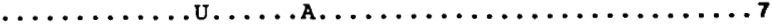

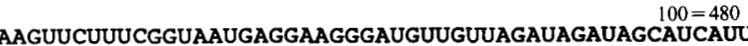
$\ldots \ldots \ldots \ldots \ldots . . \ldots . . .$. UUGA. . . . . . . . CACAUCAA. . 2

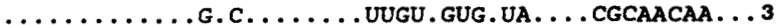
$\ldots \ldots \ldots \ldots \ldots$. . . . . . . . . UUG. . GUG. UA. . . CAU. . CAA. . 4

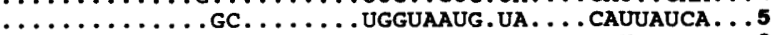
$\ldots \ldots \ldots \ldots \ldots$. . . . . . . . . U. . CAAA. .UA..... UUGG.A. . 6 $\ldots \ldots \ldots \ldots . .$. GC....... U. . CAAA. UA......UUGG.A. . 7

(b) GUGCNAGCGUUNAUCGGAAUNACUGGGCGUAAAGGGCACGCAGGCGGnCU 1

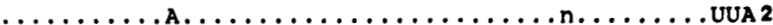

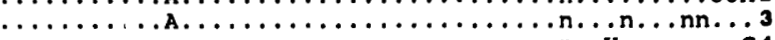

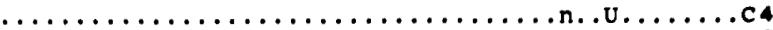

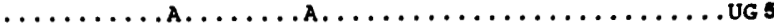

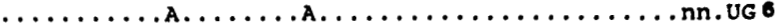

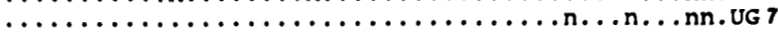

UUUAagugagaugugaAauccccgagcuuaAcuUgggaacugcauUuca 100 $\ldots \ldots \ldots \ldots$. . . . . . . . . . . . . . . . . n.U. . . . . . $\ldots \ldots \ldots \ldots$. ................................ $\ldots \ldots \ldots$..............................U4 A.................................. A........................................ A......................................

ACUGGGAGUCUAGAGUCUCGUAGAGGGGGGAAGAAUUCCAGGUGUAGCGG 1

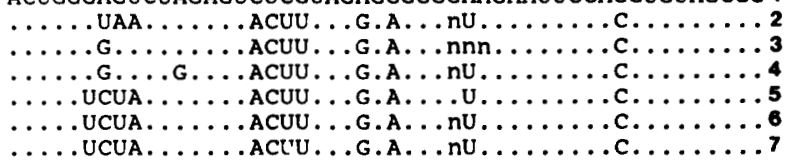

UGAAAUGCGUAGAGAUCUGGAGGAAUACCGGUGGCGAAGGCGGCCCCCCU 1

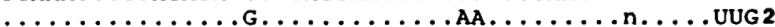
$\ldots \ldots \ldots \ldots \ldots \ldots$. . . . . . . . . . . . . . . . . . . . . . . . . . . . . . $\ldots \ldots \ldots \ldots \ldots \ldots \ldots \ldots \ldots \ldots$.................. . . . . . . $\ldots \ldots \ldots \ldots \ldots$..................... $\ldots \ldots \ldots \ldots \ldots \ldots \ldots \ldots \ldots$. . . . . . . . . . UUG 6

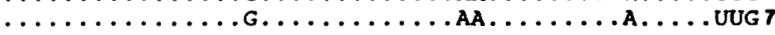

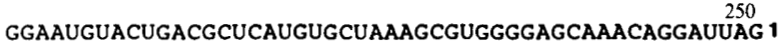

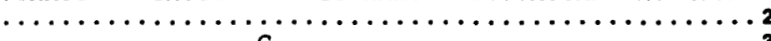

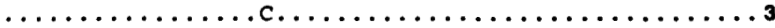

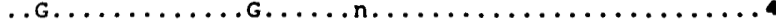

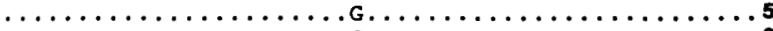

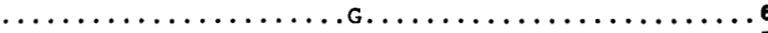

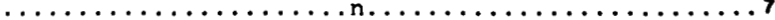

AUACCCUGgUAGUCCACGCUGUAAACGCUGUCGAUUUGgGGAUUGgGCUA 1 $\ldots \ldots \ldots \ldots \ldots \ldots \ldots \ldots \ldots \ldots \ldots \ldots \ldots \ldots \ldots \ldots \ldots \ldots \ldots \ldots \ldots$

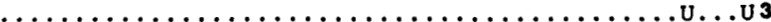

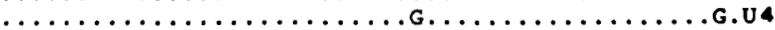

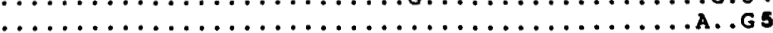

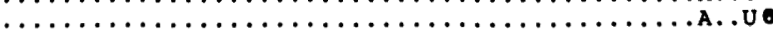

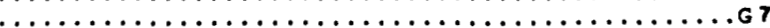

UAUGCUUGGUGCCNIUAGCUAACGUGAUAAAUCGACCGCCUGGGG

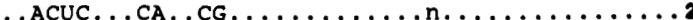

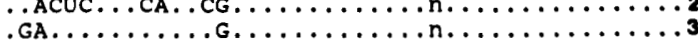

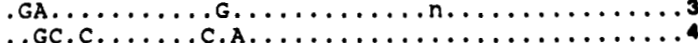
.GC.C..........................

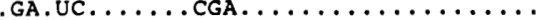

$\ldots$. UC. . . . CGA. . . . . . . . . . . . .

.GA.UC........A.................. 
acquisition of 16S rRNA sequence data has become available (Lane et al., 1985). The method is based on the bulk cellular RNA as template, oligonucleotides complementary to evolutionarily conserved regions as primers, and reverse transcriptase for chain elongation. We have applied this method to phylogenetic analysis of the Pasteurellaceae and report here partial sequence comparisons between Pasteurella multocida, Haemophilus influenzae, H. aphrophilus, Actinobacillus (Haemophilus) actinomycetemcomitans, 'A. hominis', A. equuli and $A$. lignieresii.

\section{METHODS}

Bacterial strains and growth media. The following strains were obtained from the National Collection of Type Cultures (London, UK): Actinobacillus (Haemophilus) actinomycetemcomitans NCTC 9710 (type strain); Actinobacillus equuli NCTC 8529 (type strain); 'Actinobacillus hominis' NCTC 11529 (type strain) (Friis-Moller, 1981); Actinobacillus lignieresii NCTC 4976; Haemophilus influenzae NCTC 8143 (type strain); Haemophilus aphrophilus NCTC 5906 (type strain); Pasteurella multocida NCTC 10322 (type strain). Actinobacillus and Pasteurella strains were cultured in yeast extract $(0.5 \%) /$ Difco peptone $(1 \%) /$ glucose ( $1 \%$ ) (YPD) medium, which was supplemented with NAD $(0.001 \%)$ and haemin $(0.001 \%)$ to support the growth of Haemophilus species. For growth on solid medium Columbia blood agar (Difco), or chocolate agar (Difco) plates (Haemophilus species) were used. A battery of biochemical tests, including sugar fermentations, urease and $\mathrm{H}_{2} \mathrm{~S}$ production, and requirements for $\mathrm{X}$ and $\mathrm{V}$ factors, were routinely performed to ensure the purity of the cultures. All cultures were incubated at $37^{\circ} \mathrm{C}$ with $5 \%$ carbon dioxide and without shaking.

Isolation of $r R N A$. Bulk cellular RNA was isolated using a differential $\mathrm{LiCl}$ extraction method essentially as previously described for eukaryotic cells (Auffray \& Rougeon, 1980), followed by phenol and chloroform extractions. Cultures $(500 \mathrm{ml})$ were grown to mid-exponential phase, washed once with phosphate-buffered saline (PBS), and the pellets were resuspended in $20 \mathrm{ml} 4 \mathrm{M}-\mathrm{LiCl} / 8 \mathrm{M}$-urea and incubated at $0{ }^{\circ} \mathrm{C}$ for $12-18 \mathrm{~h}$. The mixture was centrifuged at 10000 r.p.m. for $20 \mathrm{~min}$ in a Solvall SS34 rotor and the pellets resuspended in $10 \mathrm{ml} \mathrm{TE}$ buffer (20 mM-Tris/HCl, $1 \mathrm{mM}$-EDTA, pH 8.0), extracted two to four times with an equal volume of TE-saturated phenol (BRL), and finally extracted with chloroform/isoamyl alcohol $(24: 1, v / v)$. RNA of sufficient quality for use in sequencing was recovered by precipitation with two volumes of ice-cold ethanol and incubation for $30 \mathrm{~min}$ at $-70^{\circ} \mathrm{C}$. The major contaminant in these preparations was bacterial lipopolysacharide, as assessed by SDS gel electrophoresis and silver staining.

Partial sequencing of $16 S r R N A$. Partial sequences of the 16S rRNAs were obtained using avian myeloblastoma virus reverse transcriptase (Pharmacia), bulk cellular RNA as template $\left(1-3 \mu \mathrm{g} \mathrm{ml}^{-1}\right.$ ), and oligonucleotides $\left(0 \cdot 1 \mu \mathrm{g} \mathrm{m}^{-1}\right)$ complementary to conserved regions of the $16 \mathrm{~S}$ rRNA molecules as primers in chain-terminating sequencing reactions as described by Lane et al. (1985), using [ $\left.\alpha^{-32} \mathrm{P}\right] \mathrm{dCTP}\left(800 \mathrm{Ci} \mathrm{mmol}^{-1}, 29.6 \mathrm{TBq} \mathrm{mmol}^{-1}\right.$; Amersham). The data shown in Fig. $1(a)$ were obtained using the oligonucleotide primer $5^{\prime}$ GTATTACCGCGGCTGCTGGCAC 3 , and the data shown in Fig. $1(b)$ were obtained using the oligonucleotides 5'TACCAGGGTATCTAATCCTGTT 3' and 5'TCGTTGCGGGACTTAACCCAACA 3'. Oligonucleotides were synthesized using phosphoramidite chemistry on an Applied Biosystems 380A DNA synthesizer, and purified by electrophoresis on $20 \%$ (w/v) acrylamide gels followed by electroelution (Göbel et al., 1987a).

Alignment of sequences and cluster analysis. A standard algorithm (Needleman \& Wunsch, 1970) was used for sequence alignment using gap penalties (Feng et al., 1985) assigned as described below. To calculate normalized alignment scores (NAS) for each pair of sequences, positions of identity and mismatch were assigned values of ten and zero, respectively, and gaps in the alignment were penalized with values from -10 to -90 . The total was then divided by the length of the shorter sequence to give the NAS. The percentage of identities per unit length $(I / L)$ was also calculated for all pairs of sequences. Positions which could not be unambiguously aligned, or where one of the bases was not determined, were not considered in the subsequent analysis. The resulting distance matrices were analysed using the Clustan 3/PC program suite (release 3.2; Wishart , 1987) using a Tandon microcomputer equipped with a math coprocessor. The Jaccard similarity coefficient was chosen for cluster analysis with single, average (unweighted pair group arithmetic average) and complete linkage conditions, as described previously for 5S rRNA sequences (Nearhos \& Fuerst, 1987).

Fig. 1 (on facing page). Alignments of 16S rRNA sequences determined for seven members of the Pasteurellaceae. The sequences are numbered as follows: $1, P$. multocida; $2, H$. influenzae; $3, H$. aphrophilus; 4, A. (H.) actinomycetemcomitans; 5, 'A. hominis'; 6, A. equuli; 7, A. lignieresii. Positions in the sequences which are identical to the $P$. multocida sequence are indicated with a period. The letter ' $n$ ' designates positions which were not determined. (a) Base positions in the sequences are numbered consecutively, where nucleotide 1 corresponds to nucleotide 380 in the standard $E$. coli $16 \mathrm{~S}$ rRNA numbering (Brosius et al., 1978). (b) Base positions in the sequences are numbered consecutively, where nucleotide number 1 corresponds to nucleotide 543 in the standard $E$. coli $16 \mathrm{~S}$ rRNA numbering. The different oligonucleotide primers used to generate sequences for $(a)$ and $(b)$ are described in Methods. 


\section{RESULTS AND DISCUSSION}

Alignments of partial 16S rRNA sequences from seven members of the family Pasteurellaceae are shown in Fig. 1. The sequences in Fig. 1(a) correspond to Escherichia coli 16S rRNA positions $380-480$, and those in Fig. 1 (b) correspond to $E$. coli $16 \mathrm{~S}$ rRNA positions $543-888$, so that about 60 bases between the two contiguous segments are missing. These two segments contain nearly all of the variable regions V3, V4 and V5 (Huysmans \& De Wachter, 1986). It was not necessary to introduce gaps into these sequences in order to produce a good alignment; however, when a very low gap penalty $(-10$, see Methods) was used for the pairwise alignments, gaps were introduced between Pasteurella multocida and all other sequences in the region around positions 450-480 (loop 17 after Huysmans \& De Wachter, 1986). These gaps represent a compensatory insertion/deletion mutational event which retains the length of the loop (P. J. Chuba \& U. Göbel, unpublished observations). From a total of 445 positions, 24 were uncertain $(5 \%)$, and 67 of the remainder were different for the seven members of the family. Of these, 20 were different only for $P$. multocida, so that within the cluster haemophili/actinobacilli 47 of 421 positions in this region were variable. Many of these mutated positions are involved in base pairing, but we have not weighted base pairing positions differently in the construction of distance matrices as suggested by other authors (Olsen et al., 1986), since an analysis of secondary structure does not indicate that a majority of these mutations have arisen in compensatory-type events.

Identities per unit length $(I / L)$ and normalized alignment scores (NAS, gap penalty $=50$ ) were calculated by pairwise comparison of the sequences determined here, plus seven additional sequences from the literature (compiled in Huysmans \& De Wachter, 1986). These values are listed in Table 1. E. coli and Proteus vulgaris sequences served as representative of the Enterobacteriaceae (and the gamma subgroup of the purple bacteria). Agrobacterium tumefaciens and Pseudomonas testosteroni represented the alpha and beta subgroups of the purple bacteria, respectively. The Gram-positive bacterium Bacillus subtilis, the cyanobacterium Anacystis nidulans, and the archaebacterium Methanococcus vannielii were also included. Alignment scores were also calculated using higher and lower gap penalties (data not shown).

Within the family Pasteurellaceae, Pasteurella multocida was most different from all the other organisms examined ( $I / L$ score ranging from 0.887 to 0.901$)$, approximately defining the genetic variability in this region between bacteria at the family level (see below). With the exception of A. (H.) actinomycetemcomitans, the Actinobacillus sequences were remarkably similar, indicating close genotypic relatedness. The sequences of $A$. equuli and $A$. lignieresii differed at only four positions ( $99 \%$ similar), approaching the limits of accuracy of the method (Romaniuk et al., 1987), and could therefore be considered as identical within experimental error. Nonetheless, rechecking the sequencing gels at the nonidentical positions indicated that the sequences were, in fact, different. $A$. (H.) actinomycetemcomitans was more closely related to Haemophilus spp. ( $I / L=0.994$ for $H$. influenzae, and 0.951 for $H$. aphrophilus) than to the other (true) actinobacilli (mean $I / L=0.917$ ), but $H$. influenzae and $H$. aphrophilus were slightly more closely related to each other $(I / L=0.953)$ than to $A$. (H.) actinomycetemcomitans. Inspection of specific variable positions (Fig. 1) reinforced these observations. At certain positions (e.g. positions 51, 61 and 106 in Fig. 1 b), A. (H.) actinomycetemcomitans had bases in common with the two Haemophilus sequences, which differed from the three other actinobacilli. At other positions, $A .(H$. actinomycetemcomitans was the same as one or the other Haemophilus species (see positions 91 in Fig $1 a$, and 107 in Fig. $1 b$ ), suggesting divergence at different times from a common ancestor.

Fig. 2 shows dendrograms resulting from cluster analysis of the NAS matrix (gap penalty = 50) given in Table 1. Single linkage, average linkage and complete linkage results are given. Using all three methods, the branching pattern within the facultative anaerobes (E. coli, Proteus vulgaris and the Pasteurellaceae) was the same, and in all cases the archaebacterium Methanococcus vannielii clustered apart from all other species tested, forming the 'root' of the tree. As expected, $A$. $(H$.$) actinomycetemcomitans clustered with the members of the genus$ Haemophilus. The remaining three actinobacilli clustered together and separately from Pasteurella multocida. Importantly, the tree branching was consistent with previous studies of DNA/DNA hybridization between strains of Pasteurellaceae (Christiansen et al., 1981; 
Coykendall et al., 1983; Potts \& Berry, 1983; Escande et al., 1984). The Enterobacteriaceae diverged from the Pasteurellaceae at an average NAS of $7 \cdot 8$, and it would be interesting to see if the Vibrionaceae also diverge at a similar level. Interestingly, the genera Escherichia and Proteus diverge from one another at a level similar to that of Pasteurella from Haemophilus and Actinobacillus (NAS of 8.9), but the genera Actinobacillus and Haemophilus clustered more closely at an NAS of about 9.3, perhaps justifying their inclusion in an intermediate group or 'tribe'.

In contrast to the branching pattern for the facultative anaerobes, the relative branching pattern for Agrobacterium tumefaciens, Pseudomonas testosteroni, Bacillus subtilis and Anacystis nidulans did not remain constant using the three linkage methods (Fig. 2). The situation did not improve when distance matrices were calculated using higher or lower gap penalties (data not shown). This may be explained by the fact that we used a relatively small number of positions to perform the analysis, and that these sequences were relatively variable, and therefore of more limited use in examining distantly related organisms.

We expect that the continued use of direct rRNA sequencing methods will simplify and improve the taxonomic analysis of a wide variety of micro-organisms. Although accurate phylogenetic analysis of distantly related species requires the analysis of a large number of relatively constant positions, the evolutionary branching patterns of closely related organisms can be quickly established as demonstrated here. The use of these methods is increasing rapidly. For example, similar sequencing studies have recently been reported for the protozoon

Table 1. Identities per unit length and normalized alignment scores for pairwise comparisons of I6S rRNA sequences of seven Pasteurellaceae and seven other prokaryotic species

Identities per unit length are given in the lower left portion of the table, and normalized alignment scores in the upper right portion. Bacterial species names have been abbreviated using the first four letters of the species designation. The sources of sequences not determined in this work are as follows: Agrobacterium tumefaciens and Pseudomonas testosteroni, Yang et al. (1985); Anacystis nidulans, Tomioka \& Sugiura (1983); Bacillus subtilis, Green et al. (1985); Methanococcus vannielii, Jarsch \& Böck (1985); Escherichia coli, Brosius et al. (1978); Proteus vulgaris, Carbon et al. (1981).

\begin{tabular}{|c|c|c|c|c|c|c|c|c|c|c|c|c|c|c|}
\hline Species & TUME & TEST & SUBT & NIDU & VANN & COLI & VULG & MULT & INFL & APHR & ACTI & HOMI & EQUU & LIGN \\
\hline $\begin{array}{l}\text { Agrobacterium } \\
\text { tumefaciens }\end{array}$ & & $7 \cdot 51$ & $7 \cdot 48$ & 6.96 & $5 \cdot 76$ & $7 \cdot 31$ & $7 \cdot 48$ & $7 \cdot 23$ & $7 \cdot 13$ & $7 \cdot 03$ & $7 \cdot 16$ & 7.03 & 7.03 & 6.98 \\
\hline $\begin{array}{l}\text { Pseudomonas } \\
\text { testosteroni }\end{array}$ & 0.763 & & 6.98 & $6 \cdot 84$ & 6.07 & $7 \cdot 19$ & $7 \cdot 12$ & $7 \cdot 18$ & $7 \cdot 16$ & $7 \cdot 14$ & $7 \cdot 07$ & 7.09 & $7 \cdot 14$ & 7.09 \\
\hline $\begin{array}{l}\text { Bacillus } \\
\text { subtilis }\end{array}$ & 0.786 & 0.721 & & $7 \cdot 26$ & $6 \cdot 02$ & $6 \cdot 75$ & 6.74 & $6 \cdot 71$ & $6 \cdot 71$ & 6.64 & $6 \cdot 71$ & $6 \cdot 69$ & 6.74 & $6 \cdot 76$ \\
\hline $\begin{array}{l}\text { Anacystis } \\
\text { nidulans }\end{array}$ & 0.721 & 0.709 & 0.751 & & 5.99 & $6 \cdot 57$ & 6.54 & $6 \cdot 44$ & 6.49 & $6 \cdot 35$ & $6 \cdot 23$ & $6 \cdot 49$ & $6 \cdot 47$ & 6.47 \\
\hline $\begin{array}{l}\text { Methanococcus } \\
\text { vannielii }\end{array}$ & 0.602 & 0.633 & 0.641 & 0.625 & & $5 \cdot 56$ & $5 \cdot 58$ & $5 \cdot 58$ & 5.45 & $5 \cdot 56$ & 5.68 & 5.63 & $5 \cdot 58$ & $5 \cdot 56$ \\
\hline $\begin{array}{l}\text { Escherichia } \\
\text { coli }\end{array}$ & 0.793 & 0.789 & 0.745 & 0.719 & 0.620 & & 8.97 & 7.98 & $7 \cdot 68$ & $7 \cdot 72$ & $7 \cdot 65$ & $7 \cdot 75$ & 7.82 & $7 \cdot 79$ \\
\hline $\begin{array}{l}\text { Proteus } \\
\text { vulgaris }\end{array}$ & 0.798 & 0.771 & 0.773 & $0 \cdot 704$ & 0.610 & 0.932 & & $7 \cdot 89$ & 8.00 & 7.91 & $7 \cdot 89$ & $8 \cdot 15$ & $8 \cdot 12$ & 8.07 \\
\hline $\begin{array}{r}\text { Pasteurella } \\
\text { multocida }\end{array}$ & $0 \cdot 761$ & 0.754 & 0.718 & 0.682 & 0.597 & $0 \cdot 857$ & 0.836 & & $8 \cdot 87$ & 9.01 & 8.92 & $8 \cdot 76$ & 8.92 & 8.92 \\
\hline $\begin{array}{l}\text { Haemophilus } \\
\text { influenzae }\end{array}$ & 0.750 & 0.751 & 0.718 & 0.686 & 0.584 & 0.826 & 0.847 & 0.887 & & $9 \cdot 53$ & $9 \cdot 44$ & $9 \cdot 39$ & $9 \cdot 32$ & $9 \cdot 30$ \\
\hline $\begin{array}{l}\text { Haemophilus } \\
\text { aphrophilus }\end{array}$ & 0.740 & 0.761 & $0 \cdot 688$ & 0.659 & 0.594 & $0 \cdot 831$ & 0.838 & 0.901 & 0.953 & & $9 \cdot 51$ & $9 \cdot 34$ & $9 \cdot 20$ & $9 \cdot 23$ \\
\hline $\begin{array}{l}\text { Actinobacillus } \\
\text { actinomycetemcomitans }\end{array}$ & $0 \cdot 753$ & 0.742 & 0.695 & 0.667 & 0.607 & $0 \cdot 824$ & 0.836 & 0.892 & 0.944 & 0.951 & & $9 \cdot 23$ & $9 \cdot 16$ & $9 \cdot 13$ \\
\hline $\begin{array}{l}\text { 'Actinobacillus } \\
\text { hominis' }\end{array}$ & 0.741 & 0.756 & 0.716 & 0.686 & 0.602 & 0.833 & 0.861 & $0 \cdot 876$ & 0.939 & 0.939 & 0.923 & & $9 \cdot 72$ & $9 \cdot 74$ \\
\hline $\begin{array}{l}\text { Actinobacillus } \\
\text { equuli }\end{array}$ & 0.741 & 0.749 & 0.721 & $0 \cdot 684$ & 0.584 & 0.840 & 0.859 & $0 \cdot 842$ & 0.932 & 0.920 & 0.916 & 0.972 & & 9.93 \\
\hline $\begin{array}{l}\text { Actinobacillus } \\
\text { lignieresii }\end{array}$ & 0.736 & 0.744 & 0.723 & 0.684 & 0.581 & 0.838 & 0.854 & $0 \cdot 842$ & 0.930 & 0.923 & 0.913 & 0.974 & 0.993 & \\
\hline
\end{tabular}



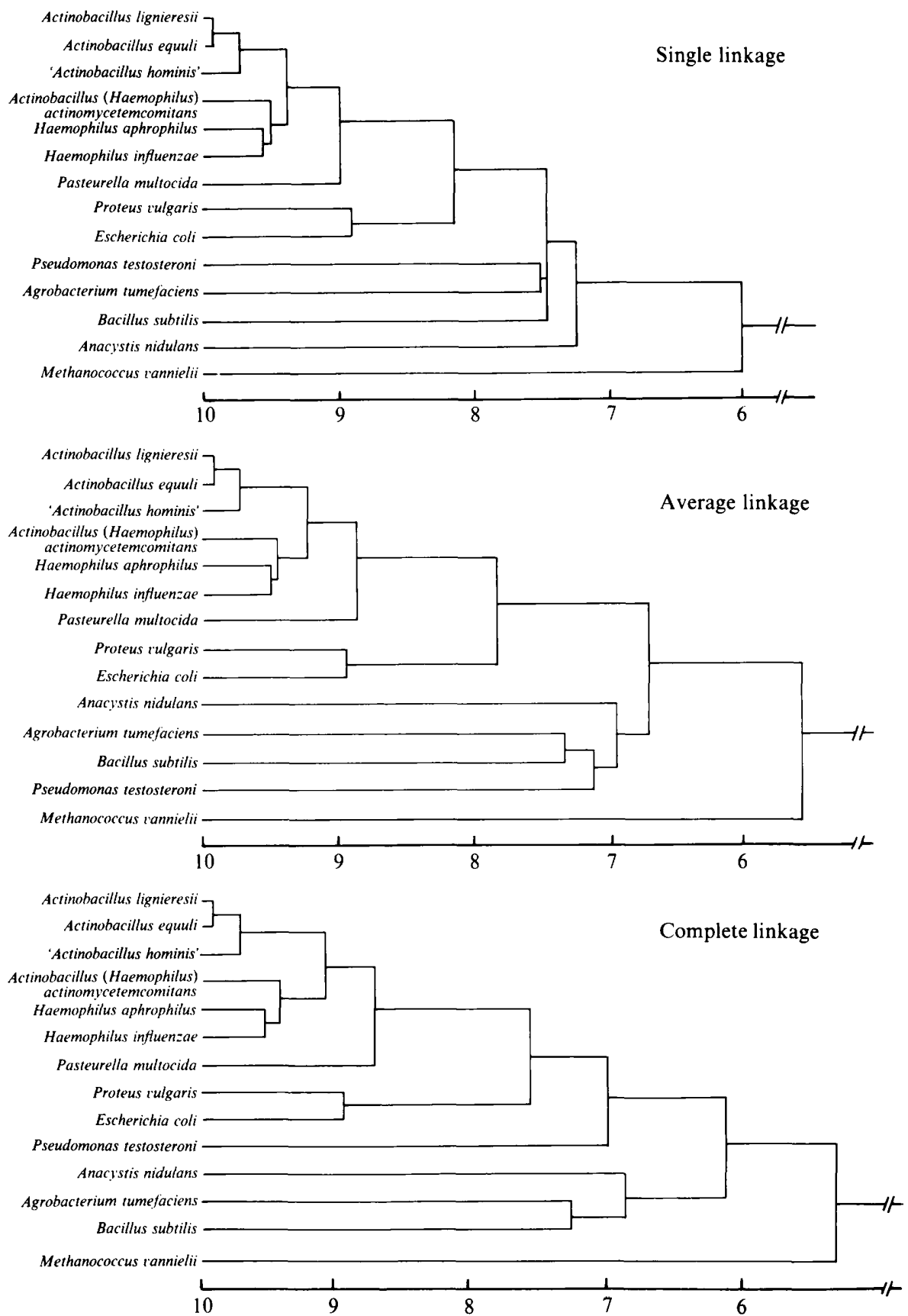

Fig. 2. Dendrograms illustrating the results of cluster analysis of the normalized alignment score matrix from Table 1 . The lengths of the branches are equivalent to the normalized alignment scores given on the scale at the bottom.

Toxoplasma gondii (Johnson et al., 1987) and the prokaryotic genus Campylobacter (Lau et al., 1987; Romaniuk et al., 1987). The PC version of the Clustan program allows cluster analysis of sequence data on a microcomputer and this will make the rRNA sequencing approach less expensive and more widely accessible to taxonomists. Aside from taxonomic and evolutionary applications, the rapid accumulation of rRNA sequence data is also important for the 
production of specific oligonucleotide probes complementary to variable regions of rRNA (Göbel et al., 1987b), which may prove to have wide applications in diagnostic medicine.

Our thanks go to Professor W. Mannheim and to Bodo Rak for their assistance and encouragement. Financial support for this project was provided by the Bundesministerium für Forschung und Technologie.

\section{REFERENCES}

Albritton, W. L., Setlow, J. K., Thomas, M. L. \& SotTNEK, F. O. (1986). Relatedness within the family Pasteurellaceae as determined by genetic transformation. International Journal of Systematic Bacteriology 36, 103-106.

Auffray, C. \& Rougeon, F. (1980). Purification of mouse immunoglobulin heavy chain messenger RNAs from total myeloma tumor RNA. European Journal of Biochemistry 107, 303-314.

Bisgaard, M., Phillips, J. E. \& Mannheim, W (1986). Characterization and identification of bovine and ovine Pasteurellaceae isolated from the oral cavity and rumen of apparently normal sheep. Acta pathologica et microbiologia scandinavica B94, 9-17.

BRONDZ, I. \& OlsEN, I. (1985). Differentiation between major species of Actinobacillus-Haemophilus-Pasteurella group by gas chromatography of trifluoracetic acid anhydride derivatives from whole-cell methanolysates. Journal of Chromatography 342, 13-23.

BRoOM, A. K. \& SNeATh, P. H. A. (1981). Numerical taxonomy of Haemophilus. Journal of General Microbiology 126, 123-149.

Brosius, J., Palmer, J. L., Kennedy, J. P. \& Noller, H. F. (1978). Complete nucleotide sequence of a $16 \mathrm{~S}$ ribosomal RNA gene from Escherichia coli. Proceedings of the National Academy of Sciences of the United States of America 75, 4801-4805.

Carbon, P., Ebel, J.-P. \& Ehresmann, C. (1981). The sequence of the ribosomal 16S RNA from Proteus vulgaris: sequence comparison with $E$. coli $16 \mathrm{~S}$ RNA and its use in secondary structure model building. Nucleic Acids Research 9, 2325-2333.

Christiansen, C., Hansen, E. \& FriIs-Moller, A. (1981). Homology between DNA from selected strains of the genera Pasteurella, Actinobacillus, and Haemophilus. In Haemophilus, Pasteurella, and Actinobacillus, pp. 158-160. Edited by M. Kilian, W. Frederiksen \& E. L. Biberstein. London: Academic Press.

CoYkendall, A. L. Setterfield, J. \& Slots, J. (1983). Deoxyribonucleic acid relatedness among Actinobacillus actinomycetemcomitans, Haemophilus aphrophilus, and other Actinobacillus species. International Journal of Systematic Bacteriology 33, 422-424.

Escande, F., Grimont, F., Grimont, P. A. D. \& BerCovier, H. (1984). Deoxyribonucleic acid relatedness among strains of Actinobacillus spp. and Pasteurella ureae. International Journal of Systematic Bacteriology 34, 309-315.

FenG, D.-F., Johnson, M. S. \& Doolittle, R. F. (1985). Aligning amino acid sequences: comparison of commonly used methods. Journal of Molecular Evolution 21, 112-125.

Fox, G. E., Stackebrandt, E., Hespell, R. B., Gibson, J., Maniloff, J., Dyer, T. A., Wolfe, R. S., Balch, W. E., RanNer, R. S., Magrum, L. J.,
ZABlen, L. B., BlaKemore, R., Gupta, R., Bonen, L., Lewis, B. J., Stahl, D. A., Luehrsen, K. R., Chen, K. N. \& Woese, C. R. (1980). The phylogeny of prokaryotes. Science 209, 457-463.

FRIIS-MolLER, A. (1981). A new Actinobacillus species from the human respiratory tract: Actinobacillus hominis nov. sp. In Haemophilus, Pasteurella, and Actinobacillus, pp. 151-157. Edited by M. Kilian, W. Frederiksen \& E. L. Biberstein. London: Academic Press.

Göbel, U., MAAS, R. \& Clad, A. (1987a). Quantitative electroelution of oligonucleotides and large DNA fragments from gels and purification by electrodialysis. Journal of Biochemical and Biophysical Methods 14, 245-260.

Göbel, U., Gaiser, A. \& Stanbridge, E. J. (1987b). Oligonucleotide probes complementary to variable regions of ribosomal RNA discriminate between Mycoplasma species. Journal of General Microbiology 133, 1969-1974.

Green, C. J., Stewart, G. C., Hollis, M. A., Vold, B. S. \& BotT, K. F. (1985). Nucleotide sequence of the Bacillus subtilis ribosomal RNA operon $r r n$ B. Gene 37, 261-266.

Huysmans, E. \& DE WaChter, R. (1986). Compilation of small ribosomal subunit sequences. Nucleic Acids Research 14 (suppl.), r73-r118.

JARSCH, M. \& BöcK, A. (1985). Sequence of the 16S ribosomal RNA gene from Methanococcus vannielii. Systematic and Applied Microbiology 6, 54-59.

Johnson, A. M., Murray, P. J., Illana, S. \& BAVERSTOCK, P. J. (1987). Rapid nucleotide sequence analysis of the small subunit ribosomal RNA of Toxoplasma gondii: evolutionary implications for the Apicomplexa. Molecular and Biochemcial Parasitology 25, 239-246.

Lane, D. J., Pace, B., Olsen, G. J., Stahl, D. A., Sogin, M. L. \& PACE, N. R. (1985). Rapid determination of $16 \mathrm{~S}$ rRNA sequences for phylogenetic analyses. Proceedings of the National Academy of Sciences of the United States of America 82, 6955-6959.

Lau, P. P., DeBrunner-Vossbrink, B., Dunn, B., Miotto, K., MacDonnel, M. T., Rollins, D. M., Pillidge, C. J., Hespell, R. B., Colwell, R. R., Sogin, M. L. \& FoX, G. E. (1987). Phylogenetic diversity and position of the genus Campylobacter. Systematic and Applied Microbiology 9, 231238.

MacINNES, J. I. \& Rosendal, S. (1987). Analysis of major antigens of Haemophilus (Actinobacillus) pleuropneumoniae and related organisms. Infection and Immunity 55, 1626-1634.

Mutters, R., Piechulla, K. \& Mannheim, W. (1984). Phenotypic differentiation of Pasteurella sensu strictu and the Actinobacillus group. European Journal of Clinical Microbiology 3, 225-229. 
Nearhos, S. P. \& Fuerst, J. A. (1987). Reanalysis of 5S rRNA sequence data for the Vibrionaceae with the clustan program suite. Current Microbiology 15, 329335.

Needleman, S. B. \& Wunsch, C. D. (1970). A general method applicable to the search for similarities in the amino acid sequence of two proteins. Journal of Molecular Biology 48, 443-453.

Olsen, G. J., Lane, E. J., Giovannoni, S. J., Pace, N. R. \& STAHL, D. A. (1986). Microbial ecology and evolution: a ribosomal RNA approach. Annual Review of Microbiology 40, 337-355.

Pace, N. R., Olsen, G. J. \& Woese, C. R. (1986). Ribosomal RNA phylogeny and the primary lines of evolutionary descent. Cell 45, 325-326.

Pohl, S., Bertschinger, H. U., Frederiksen, W. \& ManNHeIm, W. (1983). Transfer of Haemophilus pleuropneumoniae and the Pasteurella haemolytica like organisms causing porcine necrotic pleuropneumonia to the genus Actinobacillus (Actinobacillus pleuropneumoniae comb. nov.) on the basis of phenotypic and deoxyribonucleic acid relatedness. International Journal of Systematic Bacteriology 33, 510-514.

PoTts, T. V. \& BERRY, E. M. (1983). Deoxyribonucleic acid-deoxyribonucleic acid hybridization analysis of Actinobacillus actinomycetemcomitans and Haemophilus aphrophilus. International Journal of Systematic Bacteriology 33, 765-771.

Potts, T. V., Zambon, J. J. \& Genco, R. J. (1985). Reassignment of Actinobacillus actinomycetemcomitans to the genus Haemophilus as Haemophilus actinomycetemcomitans comb. nov. International Journal of Systematic Bacteriology 35, 337-341.
Romaniuk, P. J., Zoltowska, B., Trust, T. J., Lane, D., Olsen, G. J., Pace, N. R. \& STahl, D. A. (1987). Campylobacter pylori, the spiral bacterium associated with human gastritis, is not a true Campylobacter sp. Journal of Bacteriology 169, 2137-2141.

SNeAth, P. H. A. \& Stevens, M. (1985). A numerical taxonomic study of Actinobacillus, Pasteurella and Yersinia. Journal of General Microbiology 131, 27112738.

Tomioka, N. \& Sugiura, M. (1983). The complete nucleotide sequence of a 16S ribosomal RNA gene from a blue-green alga, Anacystis nidulans. Molecular and General Genetics 191, 46-50.

Wilson, A. C., Ochman, H. \& Prager, E. M. (1987). Molecular time scale for evolution. Trends in Genetics 3, 241-247.

WISHART, D. (1987). Clustan User Manual (Release 3.2). Edinburgh: Program Library Unit, Edinburgh University.

WoEse, C. R. (1987). Bacterial evolution. Microbiological Reviews 51, 221-271.

Woese, C. R., Weisburg, W. G., Hahn, C. M. PAster, B. J., Zablen, L. B., Lewis, B. J., MACKe, T. J., LudWIG, W. \& STACKebrandT, E. (1985). The phylogeny of the purple subgroup bacteria: the gamma subdivision. Systematic and Applied Microbiology 6, 25-33.

Yang, F., Oyaizu, Y., Oyaizu, H., Olsen, G. J. \& Woese, C. R. (1985). Mitochondrial orgins. Proceedings of the National Academy of Sciences of the United States of America 82, 4443-4447.

ZuCKERKANDL, E. \& PAULING, L. (1965). Molecules as documents of evolutionary history. Journal of Theoretical Biology 8, 357-366. 